\title{
Retrospective Assessment of Malnutrition among Under-Five Children in Ayder Referral Hospital, Tigray Ethiopia
}

\author{
Desta Mebrahtu $^{1}$, Girum Sebsibie ${ }^{2}$, Teklemariam Gultie ${ }^{3}$ \\ ${ }^{1}$ Department of Pediatrics, Shire Hospital, Tigray, Ethiopia \\ ${ }^{2}$ Department of Nursing and Midwifery, Addis Ababa University, Addis Ababa, Ethiopia \\ ${ }^{3}$ Department of Midwifery, Arba Minch University, Arba Minch, Ethiopia
}

\section{Article Info}

Article history:

Received Jan 23, 2015

Revised Feb 20, 2015

Accepted Apr 26, 2015

\section{Keyword:}

Kwashiorkor

Malnutrition

Marasmus

Retrospective

Underweight

\begin{abstract}
Currently worldwide there are about 60 million children with moderate acute and 13 million with severe acute malnutrition. About $9 \%$ of sub-Saharan African and $15 \%$ of south Asian children have moderate acute malnutrition and about $2 \%$ of children in developing countries have severe acute malnutrition. The objective of aim the study was to assess the magnitude of malnutrition in under-five children in Ayder referral hospital using a retrospective cross-sectional study design. This study showed that male children, 168(58.1\%), were higher than female, 121(41.9\%). Majority, 133(46\%), were in the age group b/n 12 to 24 months .More than half, 186(64.4\%) were rural dwellers. The types of malnutrition identified were Marasmus, kwashiorkor, Marasmic kwash and underweight which account for 116(40.1\%), 69(23.9\%), 54(18.7\%) and 50(17.5\%) respectively. Marasmus was the predominant type of malnutrition in all age groups of under-five malnourished children with prevalence of $40.1 \%$ where as underweight was the prevalent type of malnutrition (17.3\%). More over the infant feeding practices such as exclusive breast feeding, timely initiation of complementary feeding, and having history of breast feeding once in their life during infancy were relatively higher among the children as compared with other studies.
\end{abstract}

Copyright (c) 2015 Institute of Advanced Engineering and Science. All rights reserved.

\section{Corresponding Author:}

Teklemariam Gultie, Department of Midwifery, Arba Minch University, Arba Minch, Ethiopia.

Email: tekledb2002@gmail.com

\section{INTRODUCTION}

Globally, hunger and malnutrition are two of the most significant challenges [1]. Globally, malnutrition is a risk factor for illness and death, with millions of pregnant women and young children being affected due to infections, poor and inadequate diet. Malnutrition increases the risk and worsens the severity of infections [2]. Infants and young children are most affected by malnutrition as they have increased nutritional needs to support growth [3]. Undernourished children, as well as children with severe malnutrition, have a higher risk of dying than children with an optimal nutritional status [4].

The term "malnutrition" is usually used to describe protein energy malnutrition (PEM). The comprehensive term of PEM is universally accepted and its severe forms are called Marasmus, kwashiorkor and Marasmic kwashiorkor [5]. The term severe acute malnutrition (SAM) combines all the different forms of PEM, as SAM refers to a weight-for-height below 70\% referred to as "wasted" or presence of pitting edema in both feet referred as "edematous malnutrition". Severe forms of SAM can also be complicated by infections. The different forms still have different causes and are therefore treated differently [6]. Except for sub-Saharan Africa, the nutritional status of children is improving globally. Progress is however, hindered 
because of poverty, infection and ineffective governance. Even though global data shows a decrease in under nutrition, the malnutrition statistics for Eastern Africa are increasing [7]. There is not enough information available on the prevalence of severe or edematous malnutrition in communities. The data available from hospitals only shows the severe cases and therefore malnutrition in general is not always recorded because in most cases it is the secondary diagnosis [8]. In Central Hospital of Maputo the occurrence of malnutrition in the presence of infections, excluding measles, was greater in 2001 than in 1983. More children had marasmus than kwashiorkor in 2001 [7].

In 1990 an estimated one out of three children (177 million) younger than five years in the developing world were or had been malnourished at one stage in their lives. Malnutrition is still one of the leading causes of morbidity and mortality in children younger than five years and severe PEM still affects 2$3 \%$ of the pediatric population worldwide [9],[10].

In 2000-2002 an estimated 852 million children were malnourished, of which 815 million were in developing countries [11] and 34 million in developed countries [12]. During this time malnutrition was directly responsible for about 300000 deaths per year and indirectly for about half of all deaths in young children [11]. More than 199 million children younger than five years suffer from acute or chronic protein and energy deficiencies [12]. In 2004 an estimated 55\% of child deaths worldwide were the result of under nutrition [4].

The prevalence of stunting has fallen in developing countries from $47 \%$ in 1980 to $33 \%$ in 2000 , although progress has been uneven in different regions. In some countries rates of stunting are rising, while in many others they remain disturbingly high [13]. There are still about 800 million undernourished people in the world and in some countries severe malnutrition is the most common reason for pediatrics hospitalization. Around $27 \%$ of the children younger than five years of age in the developing world are underweight, $32 \%$ are stunted, and $10 \%$ wasted [14].

In broad categories malnutrition is classified in to three; under weight, stunting and wasting. Wasting is further classified in to three categories which include kwashiorkor, marasmus and marasmus kwashiorkor. This study tried to identify the magnitude of malnutrition among under five children in Ayder referral hospital.

\section{RESEARCH METHOD}

Study design and setting: A retrospective cross sectional study was conducted among children below the age of five years from January 2012 to December 2013. The research was carried out in Ayder referral hospital in Tigray regional state, Ethiopia. The hospital is located Mekelle city which is $783 \mathrm{~km}$ away from Addis Ababa.

Study population and sampling techniques: The sample size was calculated using the single population proportion formula based on assumed population parameter. The confidence interval, proportion of malnutrition, and margin of error were $95 \%, 0.5$ and $5 \%$ respectively. Hence, adding 5\% none response rate a sample size of 289 individual records of children diagnose with malnutrition were included. List of all children diagnosed with malnutrition in the study period were sorted from their medical records and simple random sampling techniques were used to select the study participants.

Data collection procedure and quality control: The source of data for the study was individual diagnosed with malnutrition medical record cards. The cards consisted of information recorded at admission such as, sex, age of the child, anthropometry measurements, admission medical history, physical examination and medications. The cards also recorded the follow-up anthropometry measurements and clinical features, routine medications and outcome status. All these data were collected using a uniform extraction format. Information such as the level of maternal educational are not indexed in the medical record cards. Five Nurses were recruited for data collection and two health officers for supervisors. To keep the quality of data, the data collectors and supervisors were trained for a day on how and what information they should be collecting from the record cards. On daily basis, the filled-in information extraction formats were reviewed by the supervisors and investigators to scrutiny any problems. Whenever there appears incompleteness, errors, and ambiguities of recording, the information formats were crosschecked with the source card on spot.

Statistical analysis: The data was entered in to, cleaned and analyzed using SPSS version 16 . The missing values were less than 3\% in all factors. The proportion of Malnutrition outcomes were categorized reported as 'kwashiorkor', 'marasmic kwashiorkor', 'marasmus', and 'underweight' using numbers and percentage.

Ethical statements: Ethical approval was obtained from Mekelle University, College of Health Sciences. Consents were also obtained from respective department of the hospital. In the existing system of the nation, there is no way to communicate with the patients once they get discharged from the treatment. As such, informed consent from the parents/caregivers of the children was not obtainable.

IJPHS Vol. 4, No. 2, June 2015 : $71-76$ 
The study didn't give any supplementary interventions to the participants. As it was conducted based on the medical records and was not sensitive, the consent relied on the ethical board's approval and written consent from respective department was obtained. Furthermore, the research ethical board was also aware of the issue before its approval that informed consent couldn't be obtained from the study participants. To append, any patient identifying information wasn't encoded to keep the confidentiality of the information.

\section{RESULTS AND ANALYSIS}

\subsection{Characteristics of the children}

A total of 289 children's medical record were reviewed and 168(58.1\%) female and 121(41.9\%), male. Majority 133(46\%) were in the age group b/n 12 to 24 months but it ranges from 1 to 59 months. More than half, 186(64.4\%) were rural residents while the rest were urban dwellers (Table 1). The types of malnutrition identified during the study period were Marasmus, kwashiorkor, Marasmic kwashiorkor and underweight which account for 116(40.1\%), 69(23.9\%), 54(18.7\%) and 50(17.5\%) respectively.

Two hundred seventy four (94.8\%) children were vaccinated, 14(4.8\%) were not vaccinated and the vaccination status of one child was not recorded. Two hundred seventy nine (96.5\%) had breast fed and $10(3.5 \%)$ had not. From those who got breast feeding, 200(71.7) were on exclusive breast feeding for the $1^{\text {st }}$ 6month, 73(26.2) were on mixed type of feeding, 4 children were on replacement formula feeding and two children no information in their medical record. Forty nine (17\%) children were on bottle feeding, 213(73.7\%) were not taking bottle feeding and 27(9.3\%) had no information in their medical record. seventy seven (27.6) children were initiated complementary feeding before the age of 6 month, 73(26.2) start at 6month, 115(41.2) start their complementary feeding after 6 month and 14(5\%) children had no information on their medical record (Table 2).

Table 1. Socio-demographic characterstics of the children in Ayder referral hospital

\begin{tabular}{|c|c|c|}
\hline Variables & & Number (\%) \\
\hline \multirow[t]{2}{*}{ Sex } & Male & $168(58.1)$ \\
\hline & Female & 121(41.9) \\
\hline \multirow[t]{4}{*}{ Age in months } & $<=6$ & $30(10.4)$ \\
\hline & $6-12$ & $59(20.4)$ \\
\hline & $13-24$ & 133(46) \\
\hline & $24-59$ & $67(23.2)$ \\
\hline \multirow[t]{2}{*}{ Residential address } & Rural & $186(64.4 \%$ \\
\hline & Urban & 103(35.6\%) \\
\hline \multirow[t]{2}{*}{ Weight for age } & $<60$ & $170(58.8 .9 \%)$ \\
\hline & $60-80$ & $119(41.2)$ \\
\hline \multirow[t]{4}{*}{ Weight for height } & $<70$ & 120(41.5\%) \\
\hline & $70-80$ & 101(34.9) \\
\hline & $80-90$ & $64(22.1)$ \\
\hline & $>90$ & $4(1.4)$ \\
\hline \multirow[t]{4}{*}{ Height for age } & $<85$ & $112(38.8 \%)$ \\
\hline & $85-90$ & $99(34.3)$ \\
\hline & $90-95$ & $67(23.2 \%)$ \\
\hline & $>95$ & $11(3.8)$ \\
\hline \multirow{4}{*}{ MUAC in $\mathrm{Cm}$} & $<11$ & $129(44.6)$ \\
\hline & $11-12.5$ & $117(40.5)$ \\
\hline & $12.5-13.5$ & $12(4.2)$ \\
\hline & $>13.5$ & $7(2.4)$ \\
\hline \multirow[t]{3}{*}{ Vaccination status } & Vaccinated & $274(94.8)$ \\
\hline & Not vaccinated & $14(4.8)$ \\
\hline & Not recorded & $1(0.3)$ \\
\hline \multirow[t]{2}{*}{ Ever breast feed } & Yes & $279(96.5)$ \\
\hline & No & $10(3.5)$ \\
\hline \multirow{4}{*}{$\begin{array}{l}\text { Patterns of feeding in the first } 6 \\
\text { months }\end{array}$} & Exclusive & $200(71.7)$ \\
\hline & Mixed & $73(26.2)$ \\
\hline & Only replacement & $4(1.4)$ \\
\hline & Not recorded & $2(0.7)$ \\
\hline \multirow[t]{3}{*}{ Bottle feeding } & Yes & $49(17)$ \\
\hline & No & $213(73.7)$ \\
\hline & Not recorded & $27(9.3)$ \\
\hline \multirow{4}{*}{$\begin{array}{l}\text { Initiation of complementary } \\
\text { feeding }\end{array}$} & Before 6 months & $77(27.6)$ \\
\hline & At 6 months & $73(26.2)$ \\
\hline & After 6 months & $115(41.2)$ \\
\hline & Not recorded & $14(5 \%)$ \\
\hline \multirow[t]{4}{*}{ Type of malnutrition diagnosed } & Kwashiorkor & 69(23.9) \\
\hline & Marasmus & $116(40.1)$ \\
\hline & Marasmic kwash & $54(18.7)$ \\
\hline & Under weight & $50(17.3)$ \\
\hline
\end{tabular}


Table 2. Characterstics of malnutrition with sociodemographic variables

\begin{tabular}{|c|c|c|c|c|c|}
\hline \multirow{2}{*}{\multicolumn{2}{|c|}{ Variable }} & \multicolumn{4}{|c|}{ Types of malnutrition } \\
\hline & & Kwash & Marasmus & Marasmic kwash & Under weight \\
\hline \multirow[t]{4}{*}{ Age } & 0-6 month & $3(10)$ & $12(40)$ & $12(40)$ & $3(10)$ \\
\hline & $6-12$ & $15(25.4)$ & $24(40.7)$ & $13(22)$ & $7(11.9)$ \\
\hline & $12-24$ & $38(28.6)$ & $50(37.6)$ & $22(16.5)$ & 23(17.3) \\
\hline & $24-59$ & $13(19.4)$ & $30(44.8)$ & $7(10.4)$ & $17(25.4)$ \\
\hline \multirow[t]{2}{*}{ Sex } & Male & $39(23.2)$ & 61(36.3) & $35(28.8)$ & 33(19.6) \\
\hline & Female & $30(24.8)$ & $55(45.5)$ & $19(15.7)$ & $17(14)$ \\
\hline \multirow[t]{2}{*}{ Address } & Urban & $28(27.2)$ & $38(36.9)$ & $13(12.6)$ & 24(23.3) \\
\hline & Rural & $41(22)$ & $78(41.9)$ & $41(22)$ & $26(14)$ \\
\hline \multirow[t]{3}{*}{ Vaccination status } & Vaccinated & $68(24.8)$ & 107(39.1) & 41(17.9) & $50(18.2)$ \\
\hline & Not vaccinated & $1(7.1 \%)$ & $8(57.1)$ & $5(35.7)$ & $0(0)$ \\
\hline & Not recorded & $0(0)$ & $1(100)$ & $0(0)$ & $0(0)$ \\
\hline \multirow[t]{2}{*}{ BF status } & $\mathrm{BF}$ & $64(22.9)$ & $112(40.1)$ & $54(19.4)$ & 49(17.6) \\
\hline & Not BF & $5(50)$ & $4(40)$ & $0(0)$ & $1(10)$ \\
\hline \multirow[t]{3}{*}{ Bottle feed } & Yes & $7(14.3)$ & $23(46.9)$ & $17(34.7)$ & $2(4.1)$ \\
\hline & No & $60(28.2)$ & $80(37.6)$ & $30(14.1)$ & $43(20.2)$ \\
\hline & Not recorded & $2(7.4)$ & $13(48.1)$ & $7(25.9)$ & $5(18.5)$ \\
\hline \multirow{4}{*}{$\begin{array}{l}\text { pattern of BF in the } \\
\text { first six months }\end{array}$} & $\mathrm{EBF}$ & $45(22.5)$ & $84(42)($ & $27(13.5)$ & $44(22)$ \\
\hline & Mixed BF & $17(23.3)$ & $28(38.4)$ & $24(32.9)$ & $4(5.4)$ \\
\hline & Only replacement & $2(50)$ & $2(50)$ & $0(0)$ & $0(0)$ \\
\hline & Not recorded & $2(100)$ & $0(0)$ & $0(0)$ & $0(0)$ \\
\hline \multirow{4}{*}{$\begin{array}{l}\text { Initiation of } \\
\text { complementary } \\
\text { feeding }\end{array}$} & Before 6months & $19(24.7)$ & $32(41.5)$ & 23(29.9) & $3(3.9)$ \\
\hline & At 6 months & $16(21.9)$ & $22(30.1)$ & $5(6.9)$ & $30(41.1)$ \\
\hline & After 6months & $27(23.5)$ & $52(45.2)$ & $20(17.4)$ & $16(13.9)$ \\
\hline & Not recorded & $6(42.9)$ & $4(28.6)$ & $3(21.4)$ & $1(7.1)$ \\
\hline
\end{tabular}

\subsection{Anthropometric measurement finding}

Weight for age: one hundred seventy (58.8\%) were children with weight for age of less than $60 \%$, out of these116 (68.2\%) had Marasmus and 54(31.8) were Marasmic kwashiorkor. One hundred nineteen (41.2\%) had weight for age between $60 \%$ and $80 \%$, out of these $50(42 \%)$ were under weight, 69(58\%) kwashiorkor and no child had weight for age above 80 .

Weight for height: one hundred twenty (41.5\%) were severely wasted had weight for height less than $70,101(34.9 \%)$ were moderately wasted had weight for height 70 to 80 , 64(22.1\%) were mildly wasted had weight for height between 80 and 90 and only 4 children (1.4\%) had weight for age above $90 \%$.

Height for age: one hundred twelve (38.8\%) children were severely stunted with height for age less than 85\%, 99(34.3\%) were moderately stunt between $85 \%$ and $90 \%$, 67(23.2\%) were mild stunt between $90 \%$ and $95 \%$ and only 11 children had height for age greater than $95 \%$.

MUAC: One hundred twenty nine (44.6) children had measurement of mid upper arm circumference less than $11 \mathrm{~cm}, 117(40.5 \%)$ had $11-12.5 \mathrm{~cm}, 12(4.2 \%)$ had $12.5-13.5 \mathrm{~cm}$ and $7(2.4 \%)$ had $>13.5 \mathrm{~cm}$. The remaining 24 children were not indicated for MUAC.

\section{DISSCUSSION}

From 289 malnourished children included in this study, majority (964.4\%) were from rural areas. Similarly NFCS (53) found that urban children were less affected by malnutrition (only about 17\%). On the other hand in this study from the total 278 stunted children, 34.8\%, were from urban where as majority, $65.1 \%$, were from rural area. Other researchers from South Africa have also reported that rural areas had more stunted children (54). This difference in prevalence of malnutrition among rural and urban areas may be explained by children in rural areas are more likely to be exposed to different diarrheal and other communicable diseases and they are more likely to get care from parents who are expected to be less educated and less aware of these problems.

In this study $46 \%$ of the malnourished children were in the age group of 13-24 months. Similar studies in Mozambique indicated that $55.6 \%$ of the malnourished children were in the age group of 13-24 months [7]. Even though the average age of malnourished children in this study is relatively low the peak age of the children for malnutrition is quite similar.

About half (44.6\%) the children had a MUAC of less than $11.0 \mathrm{~cm}(110 \mathrm{~mm})$ which indicated severe malnutrition and 40.5\% had a MUAC in between 11.1 and $12.5 \mathrm{~cm}$ which showed moderate malnutrition. The median MUAC for the malnourished children in this study was $11 \mathrm{~cm}$. This shows that the numbers of children who are severely malnourished are a bit higher than that of moderately malnourished. The possible explanation for such differences could be severely malnourished individuals are more likely to visit health 
facilities not only because of the malnutrition but also because of the possible complication that might happened.

Regarding immunization status of the children, 94.8\%, of the children in this study were vaccinated. Less than $40 \%$ of infants in the developing world receive immediate breastfeeding after birth. Only 39\% of babies put to their mothers breast one hour after birth despite the fact that early initiation of breastfeeding can contribute to reduced neonatal mortality through skin-to-skin contact that can prevent hypothermia (35). According to the WHO (51), exclusive breastfeeding for six months is recommended. In South Africa, the SADHS showed that $20.1 \%$ of children were never breastfed and only $11.9 \%$ of infants zero to four months old were exclusively breastfed (55). However, in this study only 3.5\% were never breast fed and, $71.7 \%$, of the children were exclusively breast fed.

According to UNICEF's 2008 report, worldwide 37\% of infants younger than six months of age are exclusively breastfed. The rate is low in Africa with less than one third of infants younger than six months receiving exclusive breastfeeding (56). Over the last ten to fifteen years exclusive breastfeeding increased in Africa from 33\% in 1995 to 38\% in 2008 (35),. According to a study undertaken in Brazil on children admitted to hospital, $19.2 \%$ of mothers never breastfed and $49.5 \%$ of children were breastfed for less than two months (57). Over all the finding on exclusive breast feeding in the current study is very high as compared with the above stated studies and the report presented by UNICEF. This variation might be due to the reason that parents of the children in this study area have better knowledge regarding the importance of breast feeding and the risk of mixed feeding as a result of the provision of continuous health education through health extension workers and other health personnel. Additionally mothers of the patients presented to hospitals could have better knowledge and health seeking behavior than those who didn't visit health facilities.

All types of malnutrition were found commonly in children from rural area. Majority of the patients with all types of malnutrition were ever breast fed, and had no history of bottle feeding. The possible reason might be that most of the clients were from rural areas in which people have no access for bottle feeding. Children from rural area practice poor personal hygiene which can predispose children to different diarrheal and other communicable diseases.

\section{CONCLUSION}

In this study types of malnutrition, distribution of malnutrition by address and sex were assessed. The overall result indicates that with a possibility of different explanations children from rural area accounted for majority of individuals who were diagnosed for the different types of malnutrition. Infant feeding practices such as exclusive breast feeding, timely initiation of complementary feeding, and having history of breast feeding once in their life during infancy were relatively higher among the children in the study as compared it with other studies.

Most of the children in the study were presented with severe acute malnutrition. Therefore growth monitoring activities should be strengthening in all levels as this has a critical importance to detect those children with malnutrition early and to treat them. More information has to be disseminated to the community through community health agents on child feeding practice and health seeking behaviors.

This study is institution based study and it might not reflect the actual problem in the community, so there has to be more research done in the community wide by using different study design.

\section{ACKNOWLEDGEMENTS}

The authors are very grateful to Ayder Hospital administrative and medical personnel. We would like to thank the school of Medicine, college of medicine and health science, Mekelle University for providing technical and financial support.

\section{LIST OF ABBREVITIONS AND ACRONYMS}

MUAC : mid upper arm circumference

UNICEF : United Nations children fund

SAM : severe acute malnutrition

PEM : protein energy malnutrition

WHO : world health organization

NFCS : national food consumption survey 


\section{REFERENCES}

[1] Duggan M., Golden B., "Deficiency diseases, in Human Nutrition”, United Kingdom: Elsevier Churchill Livingstone, 2005.

[2] Ayaya S., Esamai F., Rotich J., Olwambula A., "Socio-economic factors predisposing under five-year-old children to severe protein energy malnutrition at the Moi Teaching and Referral Hospital, Eldoret, Kenya”, E Afri Med J., vol/issue: 81(8), pp. 415-421, 2004.

[3] Lapidaries D., Steyn P., Mgijima C., Daldla N., "Review of the South African nutrition policy 1994-2002 and targets for 2007, achievements and challenges”, Nutrition, vol/issue: 21(1), pp. 100-108, 2005.

[4] Zere E., McIntyre D., "Inequities in under-five child malnutrition in South Africa”, Int J Equi Health, vol/issue: 2(7), 2003.

[5] Vorster H., Hautvast J., “A Global perspective on Food and Nutrition in, the Nutrition Society Textbook Series, Introduction to Human Nutrition. pp. 5 - 6,” United Kingdom: Blackwell Publishing, 2002.

[6] De Onis M., Frongillo A., Blossner M., "Is malnutrition declining? An analysis of changes in levels of child malnutrition since 1980”, Geneva: Switzerland, 2000.

[7] John H., "Protein-Energy Malnutrition in inpatient”, CMAJ, vol/issue: 165(10), 2001.

[8] National Food Consumption Survey (NFCS), “Children aged 1-9 years, South Africa, 1999”, Stellenbosch: South Africa, 2000.

[9] Hendricks M., Eley B., Bourne L., “Child Nutrition, in South African Health Review”, Health sys Trust, 2008.

[10] United Nations Children's Fund (UNICEF), “Management of Severe Acute malnutrition in children: Program and supply components of scaling-up an integrated approach”, New York: USA, 2008.

[11] Kleynhans C., Macintyre E., Albertse C., "Stunting among young black Children and the socio-economic and health status of their mothers/caregivers in poor areas of rural Limpopo and urban Gauteng - the NutriGro Study", South Afr J Clin Nutr, vol/issue: 19(4), pp. 163-172, 2006.

[12] Falbo R., Alves G., "Severe malnutrition: epidemiological and clinical characteristics of children hospitalized in the Institute Materno Infantil de Pernambuco, Brazil”, Cad Saúde Pública, vol/issue: 18(5), pp. 1473-7, 2002.

\section{BIOGRAPHIES OF AUTHORS}
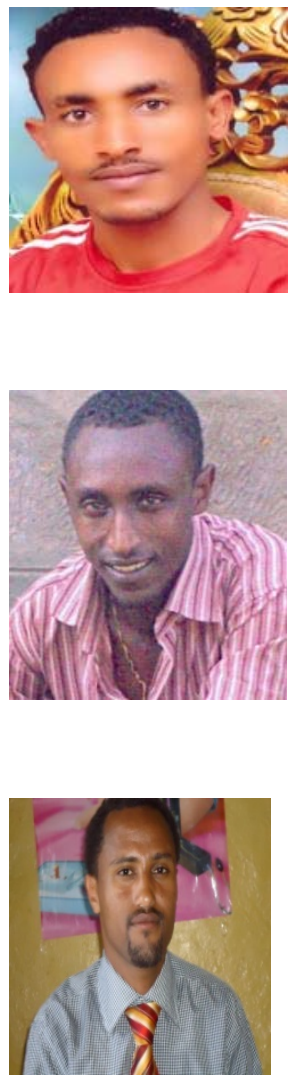

Mr. Desta Mebrahtu was born in Mekelle Ethiopia in 1991. I graduated from Mekelle university in child health and pediatrics with masters' degree. I have been working in Shire hospital Tigray Ethiopia as a pediatrics practitioner until now.
Mr. Girum Sebisibie was born in Debre Berhan, Shoa in 1985. I have attended my primary and secondary school in Hailemariaam Mamo school. I graduated from Addis Ababa University, Ethiopia with bachelor of science in Nursing in 2005 and with masters' degree in pediatrics and child health in 2012 from Mekelle University. I have been working as a lecturer and researcher for the last eight years in Addis Ababa University, Ethiopia.

Mr. Teklemariam Gultie was born in Addis Ababa, Shoa in 1988. I have attended my primary and secondary school in Dejazimach Wendirad school. I graduated from Addis Ababa University, Ethiopia with bachelor of science in 2008 and with masters' degree in Reprodcutive health in 2013. I have been working as a lecturer and researcher for the last six years in Arba Minch University, Ethiopia. Since 2014 in addition to lecturing and research activities I am working as a project coordinator of JHPIEGO Ethiopia Human resource for health project funded by USAID. I have published five research articles in different reputable journals. 